\title{
EDITORIAL
}

\section{Extreme Methods: Researching Deviance, Social Harm and Control}

\section{Olga Petintseva}

Given the particular sensitivities of much research on deviance, social harms and social control - from accessing hidden or marginalized populations, researching sensitive topics and transgressive practices, to trying to acquire a deep understanding of lived experiences and phenomenology of crime and victimization - methodological discussions have been ongoing in this thematic field since its inception. In recent decades, developments in criminology, anthropology, sociology, political sciences, development studies, media studies, and other disciplines have instigated the use of a wide array of innovative methods. Critical, reflexive and original work has been done using ethnography, narrative, visual, sensory, participatory and online methods - to name but a few.

These developments do not result from a mere thirst for intellectual stimulation and innovation for the sake of novelty per se. Rather, we need adequate tools and perspectives to understand new social phenomena and the backdrop against which they are occurring (van Swaaningen, 2018). Current globalized reality and the crisis of capitalism and state governance bring about social harms of dislocation, surveillance, incarceration, impoverishment, mind-numbing consumerism, existential uncertainty, and environmental degradation (Ferrell, 2009). If we want to foster in-depth insights and Verstehen of such dynamics, creative, reflexive and interventionist epistemologies and methodologies are a prerequisite. The field of criminology - in which much of the topics mentioned get discussed - suffers from 'methodological fetishism' in which dominant research methods contribute to mystification of social realities and the politics of everyday life (Ferrell, 2009; Young, 2011). Moving away from actuarial science and detached methods of criminological inquiry, we aim to foreground meaning, performance, unpredictability, engagement, reflexivity, creativity and, eventually, progressive transformations.

The first conference titled Between Edges and Margins: Innovative Methods in the Study of Deviance (September 2018, Ghent) was organized out of such concerns. Its goal was to foster discussions and new collaborations across disciplines and fields (such as practitioners, artists, experiential experts and academics). This vibrant and inspiring event made us think and work beyond 'edges' and 'margins' of our comfort zones. The conference and the growing network surrounding it, was established by Ghent University, the University of Kent, Utrecht University, Vrije Universiteit Brussels, the University of Porto and the Working Group on Qualitative Methodologies and Epistemologies at the European Society of Criminology. The bulk of papers included in this special issue of the Fournal of Extreme Anthropology consists of papers presented at that conference. 
The reader will first find Brunilda Pali's paper Aligning Action Research and Restorative fustice: Highlighting Epistemological Tensions, which offers a reflexive account of 'rhyming' the core principles of the two domains. This incisive paper offers a glimpse in the messy reality of action research and debunks the naive notion of 'participation' that pursues consensus void of power relations and cultural ways of thinking. Based on her experiences with action research, Pali argues convincingly that we need to rethink the meaning of conflict and participation in restorative praxis. Next, in Exile, Return, Record: Exploring Historical Narratives and Community Resistance through Participatory Filmmaking in 'Post-conflict' Guatemala, Tessa Boeykens elaborates on her study of the ways in which Guatemalan 'returnees" community 'Copal AA la Esperanza' is defending its territory against the construction of a hydroelectric dam. Boeykens' story is an engaging account about how she was mobilized by this community to make their 'shared history' by producing a (participatory) documentary film about their struggle. The paper draws on PAR principles, visual ethnography, indigenous media activism and the notion of 'performative ethnography' (Fabian, 1990). It offers broadly applicable epistemological reflections about collective knowledge production ('knowing with' instead of 'knowing about'). In his 'My Life is Like a Movie': Making a Fiction Film as a Route to Knowledge Production on Gang Political Performances in Goma, DR Congo, Maarten Hendriks also draws on Fabian's (1990) performative ethnography and goes into participatory video methodologies. He takes the discussion a step further, outlining how and why he made a fiction movie for ethnographic purposes (ethnofiction). He facilitated filmmaking and went on to write about what knowledge is made available through performance and re-enactment of everyday kigang life. As with Boeykens' paper, readers can watch the film using a $\mathrm{QR}$ code while reading. A sensory engagement is equally prominent in the work of Alison Urie, Fergus McNeill, Lucy Gathcart Frödén, Jo Gollinson Scott, Phil Crockett Thomas, Oliver Escobar, Sandy Macleod and Graeme McKerracher. Their Reintegration, Hospitality and Hostility: Song Writing and Song Sharing in Criminal Justice finds its origin in the Distant Voices project - an ongoing, interdisciplinary collaborative action research project that aims to challenge understandings of and approaches to offender rehabilitation and reintegration. The project includes collaborative song writing and song sharing. This paper particularly discusses how hostility is often disruptive and why creating and sustaining hospitable environments is vital, even though challenging. The paper also highlights authors' original methodological approach that involves collaborative participant observation, which allows 'mirroring' between differently situated participants. Next, Tim Turner who has conducted ethnographic research with drug users and drug dealers in the party spaces of Ibiza applies Bryman's (2004) Disneyization framework. He argues that (seasonal) workers are engaged in a deep form of performative labor. His paper, titled 'Fust Knocking out Pills:' An Ethnography of British Drug Dealers in Ibiza, offers methodological reflections and specifically discusses challenges encountered while conducting fieldwork in 'bounded play spaces'. Ellen Van Damme's article When Overt Research Feels Covert: Researching Women and Gangs in a Context of Silence and Fear then takes us to a different setting and discusses her ethnographic research on women and gangs. 
She offers a thorough reflection on the feeling of conducting 'covert' research, in view of the fact that her fieldwork is taking place in a context of silence and fear. Covert digital ethnography for the purpose of a research project on online dating apps is the subject of the next paper Observing participants: Digital Ethnography in Online Dating Environments and the Cultivation of Online Research Identities by Antonio Silva Esquinas, Rebeca Cordero Verdugo, Jorge Ramiro Pérez Suárez and Daniel Briggs. These authors discuss how they established different identities and how, in this way, they were able to obtain rich data from online app forums. Wytske van der Wagens's article also addresses digital realities and discusses the relevance of Actor-network Theory, which considers non-human entities as active participants of the social world. The Significance of 'Things' in Cybercrime makes the point of the importance of developing methodological principles that are informed by theory.

This special issue includes two book reviews, Thomas Raymen's Parkour, deviance and leisure in the late-capitalist city: An Ethnography reviewed by Tereza Kuldova and Arturo Escobar's Designs for the pluriverse: Radical interdependence, autonomy and the making of worlds reviewed by Nicolás Acosta García. An experimental essay Sacrum by Jeremy Biles finishes with what could be considered an inspiration for writers, eloquently stating that "to write is to be ecstatic, to descend, to return again to the Otherworld, which is never a metaphysical beyond: sacrifice without salvation."

In the fall of 2020, the second Between Edges and Margins Conference will take place in Kent and it warmly welcomes members of the Extreme Anthropology Research Network and readers of the Fournal of Extreme Anthropology.

$* * *$

Bryman, Alan. 2004. The Disneyization of Society. London: Sage.

Fabian, Johannes. 1990. Power and Performance: Ethnographic Explorations through Proverbial Wisdom and Theater in Shaba, Zaire. Madison, Wis: University of Wisconsin Press.

Ferrell, Jeff. 2009. Kill method. A provocation. Journal of Theoretical and Philosophical Criminology 1(1), 1-22.

van Swaaningen, René. 2018. Theoretical Innovation in Criminology. Paper presented at the conference: Global Issues, Cultural Perspectives (Utrecht).

Young, Jock. 2011. Criminological Imagination. London: Polity Press. 